\title{
EDUCACIÓN Y CULTURA EN LA NOBLEZA (SIGLOS XIII-XV)
}

\author{
SUMARIO
}

Personas encargadas de la educación y ámbitos donde se imparte - Modelos y programas educativos - Los aspectos concretos de la instrucción - Los nobles como promotores de educación.

Obviamente, la visión de la cultura, y de los pasos necesarios para adquirirla, de los nobles bajomedievales es muy diferente a la actual. En toda la Europa occidental, los conocimientos y técnicas que caracterizaban al caballero modélico eran el ejercicio de las armas, la equitación, la cetrería, tocar algún instrumento, danzar y practicar algún juego, fundamentalmente el ajedrez ' Probablemente, se añadía en algunos criados domésticos nociones teóricas y prácticas de servir, presentar y preparar los alimentos en la mesa de sus señores, a juzgar por la instrucción que recibe el protagonista del Espejo de Jaume Roig, del caballero que le toma por paje: «no perdí el tiempo con este discreto dueño: aprendí de él a servir bien, a manejar armas; fui cazador y cabalgador de los buenos del país, con buena mano para rienda, buen pie y espuelas; supe de halcones de toda especie y de gavilanes; de jineta para el coso, cetrería y albeitería; y bailar y tañer, y hasta cortar en la mesa; de todo me enseñó» '2. Este tipo de cultura refleja perfectamente la unión entre la actividad preferentemente guerrera, propia de la nobleza en toda la Edad Media, la función cortesana y los servicios al rey, príncipe o aristócrata, que se acentúan en los siglos XIV y XV, y alcanzan entonces su mayor refinamiento.

En el reino de Castilla, y durante el siglo XV, probablemente la mayoría de los caballeros y nobles titulados sabían también leer y escribir, como se desprende de las ambiguas frases de la Crónica de don Álvaro de Luna: "Quando fue de edad de diez años, él sabía ya todas las cosas que los otros niños quando por estonce comiençan aprender. E sabía leer e escrebir lo que convenía para

I Se encuentran varias referencias al estilo de vida de los nobles y a su educación en $\mathbf{M}$. KEEN, La caballeria, Barcelona, 1986, pp. 206 y ss.

2 Jaume RoIG, Espejo, Madrid, 1987, p. 19. 
caballero, e sabía ya cabalgar e ponerse bien a caballo, e procurava de traer limpio e bueno lo que traya, e ser muy cortés e gracioso en su fabla e contenencia»' . Sin embargo, la afición a las letras o a la ciencia no se consideraba una cualidad necesaria e incluida en las virtudes nobiliarias ${ }^{4}$. Las Generaciones y semblanzas de Fernán Pérez de Guzmán o Los claros varones Despaña de Hernando del Pulgar, que constituyen los más famosos retratos literarios de los aristócratas y prelados de la época, sólo lo mencionan como rasgo definitorio de algunos personajes concretos. $\mathrm{Y}$ en ellos adquiere una valoración positiva si se une a estas cualidades tradicionales, y negativa si la labor intelectual ocupa el tiempo del biografiado de manera preferente y casi exclusiva. Así, Fernán Pérez de Guzmán subraya que Juan II estaba adọrnado de múltiples saberes, pero le faltaba el más importante en un rey que era el de gobernar, y que el abuelo del marqués de Villena le prohibió aprender, ya «que lo quisiera para cavallero" '. A finales de la centuria, parece insistirse más en la importancia de las letras en su ejercicio conjunto con las armas, dentro del tópico común a todo el Occidente europeo, cuyo mejor exponente es $E l$ Cortesano de Castiglione.

Estas páginas de Pérez de Guzmán y las quejas posteriores de Mártir de Anglería sobre el escaso interés por el saber de los jóvenes aristócratas del tiempo de los Reyes Católicos han servido de base, entre otros textos, a P. Russell para insistir en los prejuicios contra el humanismo de nuestros nobles ${ }^{6}$. Pero, y como señala este mismo autor, el colocar las letras en una posición secundaria fue una característica común en esta época a todos los territorios del Occidente europeo, con la excepción, quizás, de Italia. Al menos, el rey Don Duarte de Portugal, contemporáneo de Juan II, habla en el Leal Conselbeiro del mal y pecado que cometería quien descuidara la administración de sus señoríos por el estudio. ' En el mismo período, tampoco parece ser muy grande el nivel

'G. Chacón, Crónica de don Alvaro de Luna, Madrid, 1940, cap. II, p. 12. Por otra parte, M. G. Gerbet afirma que la lectura y la escritura constituyen los conocimientos intelectuales mínimos de los nobles extremeños entre mediados del siglo XV y principios del siglo XVI. M. C. GERBET, La noblesse dans le royaume de Castille. Étude sur ses strucures sociales en Estrémadure de 1454 à 1516, París, 1979, p. 319.

${ }^{4}$ I. BECEIRO PITA, La biblioteca del conde de Benavente a mediados del siglo XV y su relación con las mentalidades y usos nobiliarios de la época, en Estudios en memoria del profesor $D$. Salvador de Moxó, I, «En la España Medieval», II, Madrid, 1982, pp. 135-146.

' F. PÉREZ DE GuZMÁN, Generaciones y semblanzas, Madrid, 1979. Las semblanzas de Juan II y Enrique de Villena están contenidas en las pp. 115-131 y 99-103, respectivamente. H. del Pulgar, Los claros varones Despaña, Madrid, 1971, ed. facsímil de la de Sevilla, 24 de abril de 1500 .

6 P. RuSSELl, Las armas contra las letras: para una definición del bumanismo español del siglo XV, en Temas de "La Celestina" y otros estudios. Barcelona, 1978, pp. 207-241.

'Don DuARTE, Leal Conselheiro, Vila de Maia, 1982, p. 368. 
cultural de la nobleza borgoñona, salvo en algunas individualidades ${ }^{8}$.

Desde el reinado de Alfonso XI se hace notar una creciente demanda de «letrados» para la administración regia, señorial y concejil. El progresivo auge de este grupo, compuesto en su mayor parte de individuos salidos de la universidad y dedicados a oficios jurídicos, hacendísticos y de pluma, hace que muchos miembros de la pequeña y media nobleza se interesaran por adquirir unos conocimientos especializados '. En la Corona de Aragón, si bien el conflicto entre las armas y las letras no tuvo tanto peso como en Castilla y la penetración del humanismo fue mucho mayor, tampoco parece que en el siglo $\mathrm{XV}$ hubiera un clima particularmente receptivo al sistema de ideas y actitudes intelectuales que destacaba en los territorios italianos ${ }^{10}$.

Sin embargo, también es evidente un interés de los nobles por la cultura mucho mayor que en siglos anteriores. En el reino castellano se pueden señalar varias causas para explicar esta evolución en sus rasgos más esenciales. A partir del reinado de Juan II hay que contar también con las primeras notas renacentistas y la influencia flamenca e italiana de todo tipo de arte. Por otra parte, el carácter culto de la corte regia estimuló, sin lugar a dudas, el saber y la bibliofilia de muchos aristócratas, dentro de ese afán por imitar al monarca en todos los órdenes. Aún cuando este soberano, como se ha visto, es presentado como ejemplo negativo por su falta de dotes de gobierno, impulsa las traducciones de obras clásicas, presta sus propios libros a caballeros para la realización de copias manuscritas y organiza torneos literarios en los que participan la mayor parte de los aristócratas ". Su hija Isabel I manda acudir a dos duques parientes suyos a la academia establecida en casa de Pedro Mártir de Anglería y, según cuenta el mismo humanista, «en pos de estos han venido todos los jóvenes herederos de los potentados de ambas Españas" ${ }^{12}$. La conocida frase de Juan de Lucena - «jugaba el rey, eramos todos disolutos; estudia la reina, somos todos estudiantes»- ilustra perfectamente esta situación ${ }^{13}$. En la Corona de 283-294.

${ }^{8}$ M. T. CARON, La noblesse dans le duché de Bourgogne 1315/1477. Lille, 1987, pp.

9 P. E. RUSSELL, Las armas contra las letras..., pp. 219-220.

10 S. de MOXÓ, La elevación de los "letrados» en la sociedad estamental del siglo XIV, en XII Semana de Estudios Medievales (1974), Pamplona, 1976, pp. 196-202. Para la multiplicación de este sector en el siglo XV y el ascenso social de muchos de sus miembros, véase A. RUCQUOI, Valladolid en la Edad Media, II, El mundo abreviado, Valladolid, 1987, pp. 69-94.

1 I. BECEIRO PITA, Los libros que pertenecieron a los condes de Benavente entre 1434 y 1530, «Hispania», XLIII, 154, Madrid, 1983, pp. 242-247. Para el significado de estos torneos, véase también T. J. BOUDET, conde de Puymaigre, La cour littéraire de don Juan II, París, 1873.

${ }_{12}$ Epistolario de Pedro Mártir de Angleria, en Documentos inéditos para la bistoria de España, IX, Madrid, 1955, p. 212.

13 M. BATllORI, Humanismo y Renacimiento, Barcelona, 1987, p. 29. 
Aragón, la corte de Alfonso el Magnánimo cumple un papel similar con un mayor tinte trovadoresco e italianizante, en relación con los seculares contactos con Occitania, las intensas relaciones comerciales con Italia desde el siglo XIII y la misma integración de Nápoles en el reino en este período, que se traduce además en las largas estancias del soberano en este territorio.

En fin, el incremento de las traducciones y copias al castellano de obras de la antigüedad clásica, de los Padres de la Iglesia y de escritores del "trecento» italiano amplía el abanico de lecturas posibles, algunas de las cuales conectan directamente con las formas de vida nobles. Pero, es más, es en este período cuando en las letras castellanas destacan autores emparentados con los grandes linajes. La presencia de laicos de alta cuna se inaugura en la centuria anterior con Alfonso X y en el siglo XIV se continua con su sobrino Don Juan Manuel y el canciller Pero López de Ayala, que une a su labor historiográfica la traducción de escritos en latín, que luego estarán presentes en la mayoría de las bibliotecas nobiliarias ${ }^{14}$. En el siglo XV se amplía el número de aristócratas literatos y tanto el marqués de Villena, como el de Santillana y Fernán Pérez de Guzmán, impulsan también directa o indirectamente, las traducciones del latín y de lenguas romances.

Hay que hacer dos objeciones a esta visión, un tanto optimista, sobre la afición de la aristocracia a las letras. En primer lugar, la copia manuscrita resultaba especialmente cara y lenta. Por tanto, sólo algunos grandes podían tener una gran biblioteca, aunque no haya una relación directa entre medios de fortuna y cantidades de libros. Es más, a juzgar por los inventarios conservados, las grandes colecciones estaban circunscritas a escasos individuos o familias, dadas las enormes diferencias entre las de altos personajes de mediados del siglo $\mathrm{XV}$, desde una cifra superior a más de cien volúmenes para el marqués de Santillana y los condes de Benavente y Haro, a once y diez para don Pedro de Stúñiga y el conde de Medellín, respectivamente ${ }^{15}$.

14 F. PÉREZ DE GÚZMAN en Generaciones y semblanzas, pp. 38-39 resalta expresamente estos méritos del canciller: «Por causa del son conoçidos algunos libros en Castilla que antes non lo eran, ansí como el Titu Libio, que es la más notable estoria romana, los Casos de los príncipes, los Morales de Sant Gregorio, Esidro de Sumo Bono, el Boeçio, la estoria de Troya. El ordenó la estoria de Castilla desde el rey don Pedro fasta el rey don Enrique el terçero. Fizo un buen libro de la caça, que él fue muy caçador, e otro libro Rimado del Palaçion. Hay que tener en cuenta que Pérez de Guzmán es pariente de Ayala, al igual que del marqués de Santillana.

15 Aparte de las obras ya señaladas, véase M. SCHIFF, La bibliothèque du marquis de Santillane, 2.' reimpresión, Amsterdam, 1970, M.A. LADERO QUESADA y M.C. QUINTANILLA RASO, Bibliotecas de la alta nobleza castellana en el siglo XV, en Livre et lecture en Espagne et en France sous l'Ancien Régime, (colloque de la Casa de Velázquez), París, 1981, pp. 47-59; J. N. H. LAWRANCE, Nueva luz sobre la biblioteca del conde de Haro: inventario de 1455, «El Crotalón, Anuario de Filología Española», núm. 1, Madrid, 1984, pp. 1075-1096; I. 
Además, el interés de los redactores de inventarios de bienes por señalar la encuadernación y los adornos de las portadas en metales preciosos parece indicar que muchos de sus poseedores consideraban el libro fundamentalmente como una joya o un objeto suntuoso, susceptible de una buena tasación en una almoneda.

Finalmente, entre los sectores no eclesiásticos del reino existe un desconocimiento casi general del latín. Tiene un aspecto positivo, por impulsar las traducciones, pero en contrapartida impide el conocimiento directo de los escritos clásicos. Alcanza a autores tan importantes como el marqués de Santillana, que estimaba incompleta su formación por este motivo ${ }^{16}$.

\section{PERSONAS ENCARGADAS DE LA EDUCACIÓN Y ÁMBITOS DONDE SE IMPARTE}

Sobre esta cuestión, los datos aportados por las crónicas y textos literarios son muy escasos y vagos y dejan en una total oscuridad todos los aspectos concretos del hecho educativo, y aún más en lo que se refiere a la pequeña y media nobleza. Se puede suponer, sin embargo, que la instrucción de todo el grupo participaba de unas características generales, pero con algunas diferencias según el sexo del niño o adolescente y la posición del linaje. Estas últimas pueden deducirse parcialmente de la comparación con los miembros de la familia regia, para la aristocracia, o con ricos comerciantes y artesanos, para las otras capas.

Hasta mediados del siglo XIII, los documentos se refieren habitualmente al amo como encargado de la crianza de los príncipes e infantes ${ }^{17}$. En los primeros años se realizaba en la residencia de este personaje, enclavada en sus dominios señoriales. En el reinado de Alfonso X, paralelamente a esta figura se va perfilando un ayo, de condición noble, como «home que es dado para nodrir mozo». Por tanto, se ocupa en una segunda etapa de su formación moral, guerrera y cortesana ${ }^{18}$.

BeCeiro Pita y A. Franco Silva, Cultura nobiliar y bibliotecas, cinco ejemplos de las postrimerias del siglo XIV a mediados del siglo XVI, "Historia, Instituciones, Documentos", núm. 12, Sevilla, 1985, pp. 217-350, y E. CABRERA MUÑZZ, Beatriz Pacheco y los origenes del condado de Medellin, "Anuario de Estudios Medievales», núm. 15, Barcelona, 1985, pp. 550-551.

${ }^{16} \mathrm{H}$. NADER, Los Mendoza y el renacimiento español, Guadalajara, 1986, p. 101. 256.

17 J. GONZÁLEZ, El reino de Castilla en la época de Alfonso VIII, Madrid, 1960, I, p.

${ }^{18}$ Las siete partidas, partida II, título vil,ley IV; Madrid, 1807, II, p. 46. La educación 
A propósito de la educación del futuro Enrique IV, se atestigua una duplicidad de cargos para las labores educativas; además de este ayo noble, aparece un maestro para impartir conocimientos intelectuales y elegido por su condición de letrado: «Y diole por ayo a Pedro Fenández de Córdoba, fijo del mariscal Diego Fernández, señor de Vaena. Y diole por maestro, que le mostrase Gramatica y escreuir, a vn frayre de Santo Domingo, maestro en Teología y grant letrado, que se llamaua Lope de Barrientos» ${ }^{19}$.

En el estado actual de nuestros conocimientos, es imposible decidir si esta división existió en períodos anteriores. Al decir de don Juan Manuel, los miembros de la familia real eran criados con mucha más autoridad a mediados del siglo XIII que en el siguiente ${ }^{20}$. De todas formas, el problema es la falta de datos sobre el desarrollo de estos estudios antes del final del medievo. La única noticia concreta es la instrucción en «disciplinas liberales» que busca Fernando I para sus hijos, y que debió de ser impartida por clérigos, como piensa Susana Belmartino ${ }^{21}$.

A pesar de esta escasez de datos, todo hace pensar que, al menos en algunos títulos del siglo XV, existía la misma diferenciación entre ayo y maestro que en la familia real, puesto que María Manuel, condesa de Feria a principios del siglo $\mathrm{XVI}$, hace que su capellán enseñe a uno de sus hijos ${ }^{22}$. De todas formas, esto no implica un apartamiento total del ayo de las tareas intelectuales sino que el peso de éstas solía recaer en un letrado: Así, Pedro Mártir de Anglería hace notar, hablando de los jóvenes aristócratas que acuden a su academia, que "cada uno trae a su ayo para que escuchen las explicaciones y luego en casa se las repasen y repitan conforme a mi método" ${ }^{23}$.

Salvo cuando era designado directamente por el monarca, en prueba de especial interés por el niño, el ayo debió de ser un criado especializado de los padres o de los parientes encargados de la tutela y, a juzgar por esta epístola de Anglería y la crónica de El Victorial, habitaría en la residencia de éstos, juntamente con su discípulo ${ }^{24}$.

dada por los ayos en buenas maneras y etiqueta se muestra también en la partida II, título VII, leyes V-VIII, Pp. 47-51.

19 Lope de BARRIENTOS, Refundición..., p. 83 y p. 115.

20 Don Juan MANuel, Libro de las armas, p. 123

21 S. BELMARTINO, Estructura de la familia y "Edades sociales" en la aristocracia de León y Castilla según las fuentes literarias e bistoriográficas (siglos X-XIII) "Cuadernos de Historia de España», núm. 47-48, Buenos Aires, 1968, p. 295.

${ }^{22}$ M. C. GERBET, La noblesse dans le royaume de Castille. Étude sur ses structures sociales en Estrémadure de 1454 à 1516, París, 1979, p. 319.

${ }^{23}$ Epistolario de Pedro Mártir de Angleria, p. 212.

${ }^{24}$ Gutierre Díez De GaMes, El Victorial. Crónica de don Pero Niño, conde de Buelna, Madrid, 1940, p. 84: «Acaeçio una bez, seyendo Pero Niño avn en poder de vn su ayo, como 
Esta figura es una de las que en la Plena y Baja Edad Media alcanza mayor valoración, y tanto en la aristocracia como en la monarquía. La relación con el ayo es presentada en los textos con un carácter familiar, como un segundo padre y sustituto del progenitor natural. Posee una especial superioridad moral, en virtud no sólo de su mayor edad y experiencia sino de ser el autor de la crianza, en una representación mental similar a la de los señores con respecto a los "criados», en el sentido literal de la expresión ${ }^{2 s}$.

Nueva prueba de la importancia que se concedía a su misión es el desarrollo de una literatura didáctica, de "castigos» o enseñanzas dirigidos explícitamente a la formación de futuros monarcas y, secundariamente, de hijos de las grandes Casas, aunque sus consejos seguían teniendo validez para la edad adulta. Sobre todo en las obras escritas durante el siglo XIII y en la primera mitad del XIV, la enseñanza adopta la forma de parábola o apólogo, siguiendo una tradición que hunde sus raíces tanto en las predicaciones occidentales como en las fuentes islámicas ${ }^{26}$. Muchas de ellas están estructuradas como respuestas dadas por un maestro de edad a las preguntas de toda clase de un discípulo joven. El modelo más famoso de estos dos hombres es el formado por Aristóteles y Alejandro Magno, plasmado en la literatura castellana en el Libro de Alexandre. Los escritos de esta primera etapa expresan además claramente esta finalidad educativa: El libro de los doze sabios, Castigos y documentos, para la formación respectiva de los futuros reyes Alfonso X y Fernando IV, y el Libro infinido, que realiza don Juan Manuel para su hijo don Fernando, y participan de esta estructura, aunque no tengan dedicatoria expresa, el Libro del Caballero $y$ del Escudero y Libro de los estados, de este autor. En el área catalana, tienen su paralelo en el Livre de saviesa, dedicado por Jaume I a su hijo Jaume II el Justo, y la Doctrina puerilis, de Ramon Llull para su hijo ${ }^{27}$. En la época posterior,

suso dixe, vino de abentura vn hombre ytaliano de naçión que venia a Santigo. Vino a casa de su padre de Pero Niño, e de su madre doña Ynés Lasa, e vió a este donzel Pero Niño...».

${ }^{25}$ Las siete partidas, partida IV, título XX, leyes I y II, Madrid, 1972, III, Pp. 115116.

Para la valoración del ayo en la Plena Edad Media, véase S. BelmarTiNO, Estructura de la familia..., pp. 287-295.

${ }^{26} \mathrm{P}$. GROUSSAC, Le livre de "Castigos e Documentos" attribué au roi $D$. Sanche IV, "Revue Hispanique», XV, 1906, p. 227. Véase también I. BECEIRO PITA y A FranCO SILVA, Cultura nobiliar y bibliotecas..., p. 289.

27 Carmen MARTínEZ BLANCO, «El niño como destinatario del texto literario en las literaturas peninsulares (Edad Media)». Comunicación presentada en las Jornadas de Literatura vasco-francesa-hispánica celebradas en San Sebastián del 22 al 25 de junio de 1988. Agradezco a esta investigadora el ofrecimiento del texto de su comunicación cuando se encontraba inédito. 
estas obras tienen un carácter más filosófico y didáctico-político y están dirigidos a reyes y señores. La mayoría está dentro de la tradición del «Regimiento de príncipes" y tiene como modelo el Regimine principum de Egidio de Colonna o Egidio Romano. En Castilla, fue traducido y glosado por Juan de Castrojeriz para instruir al futuro Pedro I, y en el siglo XV se convertirá en uno de los libros más difundidos entre la nobleza laica ${ }^{28}$. Por lo demás la influencia de este tratado parece ser común a todo el Occidente europeo y se hace notar también en otras áreas peninsulares, y más concretamente en el Livro dos conselbos de don Duarte de Portugal y, un siglo antes, en Cataluña, en el Regiment de princeps e de comunitats de Eiximenis y, de manera más indirecta, en la Crònica de Ramón Muntaner, puesto que su objetivo es servir como espejo de futuros monarcas ${ }^{29}$.

¿Hasta qué edad del discípulo se extendía la labor del ayo? La Crónica de don Pero Niño nos dice que el adoctrinamiento de éste duró de los diez a los catorce años ${ }^{30}$, edad en que al varón se le considera apto para enfrentarse a la vida adulta, en la medida en que puede realizar juramentos y contraer matrimonio. También a don Álvaro de Luna le asignan ayo los tíos que le acogen al quedarse huérfano a partir de los diez años, cuando ya ha recibido la primera formación ". Tal vez sus funciones comenzaran, por lo general, entre los siete y diez años del alumno, que es cuando -según entonces se pensaba- éste tenía ya discernimiento suficiente para sacar provecho de sus consejos.

La siguiente etapa significa, al mismo tiempo, la continuación del aprendizaje y el comienzo de su promoción política y cortesana. Cuando no se trataba del heredero de un gran señorío, esta promoción tenía lugar mediante la estancia en la vivienda de un hermano o pariente, cuyo patronato le ofrecía mejores condiciones de ascenso. En muchas ocasiones, éstos adolescentes unían la condición de parientes a la de criados y se educaban conjuntamente con los hijos del señor de la Casa o, en el caso de que el pariente fuera un eclesiástico, con los clérigos vinculados a él y en los mismos centros de enseñanza que éstos.

Algunos hijos de nobles se integraban en la Casa regia, independientemente de pasar o no por el escalón intermedio del patronato familiar. La costumbre de criar a los hijos de los «omes honrrados», expresada en las Partidas ${ }^{32}$, se

${ }^{28}$ Para el significado ideológico de la posesión de este libro en Castilla, véase I. BECEIRO PITA, Los estados señoriales como estructura de poder en la Castilla del siglo XV, en Realidad e imágenes del poder. España a fines de la Edad Media, Valladolid, 1988. Edit. Ambito p. 322, dir. A. Rucquoi.

${ }^{29}$ C. MARTíneZ BlanCO, El niño como destinatario...

30 Gutierre DíEZ DE Games, El victorial, Crónica de don Pero Niño... pp. 64-73.

${ }^{31}$ G. Chacón, Crónica de don Alvaro de Luna, pp. 12-13

${ }^{32}$ Las siete partidas, partida II, título IX, ley XXVII, Madrid 1807, II, pp. 82-83. 
atestigua ya en el siglo XI, y tiene su mejor ejemplo en el que luego será conocido como el Cid Campeador. En la primera mitad del siglo XV, el aprendizaje militar y cortesano se constata en la Crónica de don Álvaro de Luna ${ }^{33}$. Hasta finales de la centuria no hay indicios claros de un estudio propiamente dicho y vinculado al palacio: el de la casa de Pedro Mártir de Anglería, fundado en 1492, como ya se ha dicho, a iniciativa de la reina. Allí, el humanista se esfuerza por desterrar el desprecio de estos jóvenes por las letras, en sucesivas lecciones impartidas por el maestro, escuchadas por los estudiantes y repasadas posteriormente en las respectivas casas ${ }^{34}$. Si el contenido de esta academia es renacentista, también recoge la tradición medieval de las escuelas palatinas, cuyos antecedentes más lejanos y destacados se encuentran en la España visigoda, la Francia carolingia y la Inglaterra sajona entre los siglos VII al $\mathrm{X}$.

De la instrucción de los hijos de la media y baja nobleza territorial y de los caballeros urbanos apenas hay datos. Puede ser que tuvieran ayo, pero lo más probable es que buena parte de los primeros se educara en la Casa señorial a la cual estaba vinculada su familia.

El otro medio de lograr una formación es el acudir a las escuelas eclesiásticas y municipales. En el reino portugués y en Inglaterra no era raro el envío de nobles adolescentes a centros monásticos ${ }^{35}$. En Castilla, las noticias conservadas sobre el tema son muy escasas, pero hay que tener en cuenta las fundaciones creadas a mediados del siglo XV a título individual, como la del arcediano de Cuéllar en esta villa, o el interés de los concejos en esta misma época por establecer escuelas locales para la enseñanza de la lectura y la escritura, como ocurre en Burgos y Villalón de Campos ${ }^{36}$.

Posteriormente, y al igual que sucedía en Portugal, algunos de estos hidalgos y caballeros pasarían a estudios universitarios ${ }^{37}$. Muy probablemente se trataría en su mayor parte de miembros de familias de letrados o de la oligarquía municipal, y también de todo tipo de individuos de alto rango destinados a la clerecía.

La educación de las jóvenes parece estar más circunscrita al ámbito familiar y a un grupo reducido formado por la madre y sus camareras o criadas,

33 G. Chacón, Crónica de don Alvaro de Luna, pp. 14.

${ }^{34}$ Véase supra n. 12.

3 A.H. de Oliveira Marques, Portugal na crise dos seculos XIV e XV, "Nova Historia de Portugal», IV, Lisboa, 1986, pp. 407-408, y E. POWER, Mujeres medievales, Madrid, 1979, p. 100 y ss.

${ }_{36}$ A. Ubieto ARTETA, Colección diplomática de Cuéllar, Segovia, 1961, pp. 448-466, V.V.A.A., Burgos en la Edad Media, Burgos 1986, p. 494, y Archivo Municipal de Villalón de Campos. Actas del Concejo de 1468. Sec. 8, Leg. 2.

"A.H. de Oliveira MARQues, Portugal na crise... p. 408 
en consonancia con la insistencia de Alfonso X en la guarda especial de las infantas: «Amas e ayas deuen ser dadas a las fijas del Rey, que las crien, e las guarden, con grand femencia. Ca si en los fijos, deue ser puesta muy grand guarda... mayor la deuen auer las fijas, por que los varones andan en muchas partes, e pueden aprender, de todos, mas a ellas, non les conuiene de tomar enseñamiento sino del padre o de la madre, o de la compaña que ellos les dieren.... ${ }^{38}$. No obstante, los medios de acceder a la educación son esencialmente los mismos; un ayo o aya para las jóvenes de más alto rango, la casa de los parientes o el palacio regio, ambos mencionados en las «Memorias» de Leonor López de Córdoba ${ }^{39}$, o también el servicio de una gran dama.

Las diferencias parecen radicar fundamentalmente en dos puntos: por una parte, debió de ser mayor la acogida en conventos de doncellas que de varones jóvenes, ya que sólo hay noticias claras de las primeras, tanto a través de las creaciones literarias como en la referencia de Leonor López de Córdoba a la crianza de su madre en un convento, de donde fue sacada para contraer matrimonio ${ }^{40}$.

En segundo lugar, existió un claro recelo al estudio femenino, por considerarse superfluo para quien tenía su función en el ámbito privado del hogar. El más destacado representante de los que propugnan su apartamiento de la ciencia es Fernán Pérez de Guzmán, quien juzga como deshonesta la presencia de las mujeres entre los escolares. En cambio, Fray Martín de Córdoba, en un libro dedicado a la futura reina Isabel, admitirá el saber en las mujeres, pero sólo para reinas, princesas y muy altas dueñas, y a causa de la necesidad de administrar sus estados. Esta postura es similar a la de otros autores del Occidente europeo, como el italiano Barberino, y moderada con respecto al mismo Pérez de Guzmán, Felipe de Navarra o el Caballero de la Tour Landry, ya que los dos últimos prohiben la lectura y la escritura femenina o aconsejan leer sólo para el conocimiento de las Sagradas Escrituras ${ }^{41}$.

${ }^{38}$ Las siete partidas, segunda partida, título VII, ley XI, Madrid, 1807, p. 51 . Véase también Reyna PASTOR, Para una historia social de la mujer bispano medieval. Problemática y puntos de vista, en La condición de la mujer en la Edad Media, Madrid, 1986, pp. 287288.

39 R. AYerbe-ChauX, Las memorias de doña Leonor López de Córdoba, "Journal of Hispanic Philology", 2, 1977-78, pp. 11-33.

40 La medición literaria más explícita es la de la doncella sabia de El libro del caballero Zifar. F. LÓPEZ ESTRADA, Las mujeres escritoras en la Edad Media castellana, en La condición de la mujer..., pp. 15-16.

Para la madre de Leonor López de Córdoba, véase R. AYERBE-ChaUX, Las memorias..., pp. 22-23.

41 F. LOPEZ ESTRADA, Las mujeres escritoras..., pp. 19-21; Fray Martín de CÓRDOBA, Jardín de las nobles doncellas, en Prasistas castellanos del siglo XV, II, B. AA. EE, 171, Madrid, 1964, p. 103; M. I. PÉREZ de TUDELA VELASCO, Acerca de la condición de la mujer castellano-leonesa durante la Baja Edad Media, en «En la España Medieval», IV, Estudios dedicados al profesor D. 
No es de extrañar, entonces, que la literatura didáctica para mujeres sea mucho menos abundante que la dirigida a los varones. Los cuatro escritos de esta orientación en castellano datan todos del siglo XV y dos de ellos están dedicados a la infanta Isabel, que posteriormente llegará a ser la Reina Católica, aunque el Jardín de nobles doncellas, de Fray Martín de Córdoba, pertenece más bien al género del «regimiento de príncipes». En las otras áreas peninsulares, su escasez es mucho más acusada, pues sólo hay constancia de Lo libre de les dones de Francesc de Eiximenis, entre 1392 y $1398^{42}$.

De todas formas, no parece que los detractores del estudio en la mujer tuvieran una influencia decisiva en los grupos acomodados. No hay pruebas de que asistieran a los mismos colegios de gramática que los varones, y aún menos a las Universidades, salvo a título excepcional, como Teresa de Cartagena, que tenía estudios universitarios. Sin embargo, en las ciudades francesas, inglesas y alemanas de este período se atestiguan escuelas elementales para cada sexo. En lo referente al reino de Castilla, no se ha encontrado documentación sobre la presencia de muchachas nobles en estas escuelas, pero hablan bien a las claras de su participación en el aprendizaje la fama que alcanzó Beatriz Galindo en la corte de Isabel I, las escritoras como Leonor López de Córdoba, Teresa de Cartagena y Florencia Pinar, y el consejo de Hernando de Talavera a la cuarta condesa de Benavente de que pase algún tiempo en una buena lección, aunque lo tase en media hora al día después de comer, y que además puede ser sustituida por «alguna recreación o de honesta o provechosa habla con algunas buenas personas, o de alguna honesta música» ${ }^{43}$.

\section{MODELOS Y PROGRAMAS EDUCATIVOS}

Los textos más extensos y detallados sobre formas concretas de instrucción son los que se refieren, en cuanto a los primeros, a héroes literarios revestidos de especiales cualidades que los colocan por encima de los seres reales, o los que reflejan las opiniones de algunos de los escritores más destacados del momento,

Ángel Ferrari Núñez, II, Madrid, 1986, pp. 767-796; E. POWER, Mujeres medievales, pp. 9899.

12 C. Martínez Blanco, El niño como destinatario del texto literario...

${ }^{43}$ E. POWER, Mujeres medievales, pp. 104-106. A. DeYERMOND, Spain's First Women Writers, en Women in Hispanic Literature. Icons and Fallen Idols, ed. de Beth Miller Berkeley and Los Angeles, 1983, pp. 37-55. El texto de Fray HernANDO de TALAVERA se encuentra en la Biblioteca de El Escorial, M S. IV-b-26, fols. 1a-27 v. Ha sido comentado por I. BECEIRO PITA en La mujer noble en la Baja Edad Media castellana, en La condición de la mujer..., pp. 312-313. 
con un fuerte sentido didáctico, expresado directamente o a través de un personaje presentado como modelo de conducta. Esta es la razón de englobar su análisis bajo este epígrafe.

Uno de los grandes modelos míticos de la niñez, adolescencia y juventud caballeresca en la Edad Media es Alejandro Magno. La fascinación por esta figura se debe, a grandes rasgos, a la preocupación por resucitar la antigüedad por parte de las escuelas del siglo XII, al interés por relacionar la sociedad de la época con el pasado, a la visión analógica de Carlomagno y su caballería con la medieval, y a la vinculación del héroe con Aristóteles, el filósofo más reputado del mundo clásico a partir del siglo XII. En definitiva constituye la unión entre la «materia de Roma» y la aventura épica, tan cara a la nobleza ${ }^{44}$.

Pues bien, el Libro de Alexandre, de mediados del siglo XIII, nos muestra cómo el niño Alejandro aprende a leer a partir de los siete años y tiene como maestros a los mejores sabios de Grecia, que le enseñan las siete artes liberales, es decir, el trivium y el quadrivium de las escuelas medievales. Aristóteles actúa como ayo desde esa edad y, en un claro anacronismo de la obra, le hace aprender el mester de clerecía, la gramática latina, la lectura y escritura, las figuras del silogismo lógico, la versificación, el arte musical y la memorización de autores sobresalientes. Aparte de este aprendizaje tan laico, que contrasta con los datos conocidos para personajes históricos posteriores, el carácter excepcional del héroe se pone de manifiesto en los prodigios que acompañan a su nacimiento, en una exaltación de la realeza que recuerda a la que expresaban los cronistas franceses del siglo XIII para Felipe Augusto y San Luis "s.

Tampoco sirve como ilustración de la realidad la comparación con el Blaquerna de Raimundo Lulio. Dejando a un lado las diferencias entre la Cataluña del siglo XIII y la Castilla bajomedieval, también resultan los conocimientos del protagonista muy por encima de lo habitual. En efecto, además de la edad tan temprana en la que se inicia, no sólo sabe leer, escribir y gramática latina sino que está versado en música, filosofía, geometría, astronomía, y medicina. Acude con el criado que le instruye a la escuela urbana, donde aprende teología, que luego ampliará en un centro específico. Esta educación, a la que se une la temprana asistencia a la iglesia para ir familiarizándose con el ayudar a misa, es de tipo clerical y sobrepasa en mucho a la del eclesiástico de nivel medio.

44 M. KeEN, La caballeria, pp. 145-146. Para la relación entre el Libro de Alexandre, el Blanquerna y los temas educativos tiene mucho interés el artículo de J. L. MARTín RODRíGUEZ, El niño en la Edad Media hispánica, "Stvdia pedagógica», núm. 6, Salamanca, 1980, pp. 39-53.

45 El Libro de Alexandre, ed. ce J. Cañas Murillo, edit. Cátedra, Madrid, 1988, pp. 139-140. Los prodigios, que según loṣ cronistas acompañan al nacimiento de estos soberanos franceses, han sido analizados por A. LEWIS en Le sang royal, París, 1986. 
El castellano don Juan Manuel, como corresponde a su condición de miembro de la familia regia, es el autor peninsular que mejor describe las formas de vida aristocrática. El fragmento del Libro de los Estados sobre la educación de los hijos de los emperadores es el texto más amplio y pormenorizado sobre estos temas. Coincide con el Blanquerna en la idea de que a los niños hay que tratarlos con severidad, como preparación para soportar los rigores de la vida, lo que en don Juan Manuel significa fundamentalmente la rudeza de las actividades guerreras.

La preocupación de conjugar las armas con las letras parece preludiar la de los humanistas del Renacimiento. En el primer aspecto, el relato de los primeros pasos en la equitación parece ajustado a la realidad, e incluso con detalles pedagógicos: «luego que los ninnos comiençan andar, que deuen a las vezes subir los en las vestias et [vayan] omnes en pos dellos que los tengan... Et desque vieren que se puede tener en cauallo, deuen le fazer andar poco a poco en él, fasta que sin reçelo lo pueda remeter. Et después, cada día faziendo más, fasta que se atreua a poner espuelas a qualquier cauallo. Otrosí, deuen le mostrar caçar et correr monte et bofordar et armarse et saber todos los juegos et las cosas que pertenesçen a la cauallería, por que estas cosas non enpesçen al leer, nin el leer a estas cosas. [Et] deuen lo fazer en esta manera [et] ordenar la semana en esta guisa: el domingo oyr la missa [et] si fuere cantada será mejor; et despues de missa, caualgar et trebejar fasta que sea ora de comer. Et desque ovieren comido et estudieren vn rato con las gentes fablando et departiendo, entrar en su camara si quisiere dormir, [et] sinon estar y vna pieça hasta que se asosiegue la vianda. Et desque fuere contra la tarde, puede yr trebejar de pie o de bestia en lo que tomare mayor plazer, fasta que sea ora de çena... Et el lunes, leuantese de grant mannana a oyr la missa, et si fuere de hedat que pueda andar de cauallo et sofrir la fortaleza del tiempo, non deue dexar, por fuerte tienpo que faga, de yr a caça en cauallo"... Sin embargo, la dedicación de la mayoría del tiempo al estudio parece más bien una aspiración, reflejo de su propia dedicación y aficiones, y si se cumplió en algún caso fue excepcionalmente y con hijos de nobles especialmente interesados en estos temas: «Et desque tornare de caça et oviere comido et folgado, commo es dicho, en la tarde, deue oyr su lecçion et fazer conjugaçion et declinar et deruiar o fazer prouerbio o letras. Et otro día martes, despues que oviere oydo missa deue oyr su lecçion et estar aprendiendo fasta ora de comer; et desque oviere comido, folgar, como desuso es dicho, et tornar a leer et a repetir su lecçion et fazer conjugaçion et las otras cosas, como es dicho; [et] pasar así toda la semana leyendo vn día et caçando otro; et el sabado repetir et confirmar todas las lecciones de la semana». Además, si la recomendación del hábito de los libros de historia se inserta perfectamente en los gustos del grupo nobiliar, no puede menos de causar extrañeza la edad de cinco años para iniciarse en la lectura, ya que no se 
corresponde con ninguno de los otros textos, como la ya indicada Crónica de don Álvaro de Luna, incluso supera a la del mítico Alexandre. Finalmente, hay que tener en cuenta el también mencionado problema del desconocimiento del latín entre los aristócratas castellanos: «E de[s] que pasare[n] de çinco años adelante, deuen començar poco a poco a las mostrar leer, pero con falago e sin premia. Et este leer deue ser tanto, a lo menos, fasta que sepan fablar et entender latin. Et despues, deuen fazer quanto pudieren porque tomen plazer en leer las coronicas et de los fechos de armas eten de cauallerías que acaesçieron; et en como los grandes sennores llegaron a grandes estados por su vondat et por su esfuerço; et quanto mal pasaron en su vida et quan mal acabaron et quan mala fama dexaron de si los enperadores et reys et grandes sennores que fizieron malas obras et fueron medrosos et flacos de coraçon" ${ }^{46}$. Por tanto, se puede considerar el conjunto de este texto como una mezcla de ideales y descripción de la realidad sobre la educación aristocrática.

\section{LOS ASPECTOS CONCRETOS DE LA INSTRUCCIÓN}

En un mundo penetrado por la religión como es el medieval, no es de extrañar que la iniciación a las prácticas religiosas sea previa a cualquier otro aprendizaje. Don Juan Manuel y Raimundo Lulio insisten en que desde pequeño se acostumbre el niño a rezar y a oir con devoción la misa, los oficios divinos y las horas canónicas y el valenciano San Vicente Ferrer, en sus sermones, sitúa en tres años la edad para empezar el rezo. Esta importancia dada a la devoción y a la liturgia enlaza, en la edad adulta, con la abundancia de misales, breviarios, salterios y libros de horas en las bibliotecas nobiliarias del siglo XV y principios del XVI ${ }^{47}$

Se encuentran unidas a esta religiosidad las enseñanzas morales, que ocupan la mayor parte de los pasajes literarios o de las crónicas referidos a la educación, y corren a cargo del ayo, del padre o, muy en segundo lugar, de alguna figura masculina y de edad que haga sus veces. Tienen su plasmación en esos escritos didácticos ya citados.

La pieza clave de la instrucción caballeresca es la equitación, caza y justas cortesanas. Todo ello forma un conjunto encaminado a la preparación del futuro guerrero, a mantener su condición física y a enardecer el ánimo en

46 Don Juan Manuel, Libro de los Estados, en Obras completas, I, Madrid, 1982. Ed. de J. M. Blecua. Edit. Gredos, p. 324.

47 J. L. MARTín RODRíGuez, El niño en la Edad Media..., p. 42; I. BeCEIRO PITA y A. Franco Silva, Cultura nobiliar y bibliotecas..., pp. 288-289 y 300-301. 
tiempo de paz. A juzgar por los escritos de don Juan Manuel, por el Leal Conselheiro del portugués don Duarte y por los mismos pasajes de las crónicas castellanas, el aprendizaje era fundamentalmente de tipo práctico ${ }^{48}$. Sin embargo, las obras encaminadas a porporcionar información suplementaria a los que no dominaran estas técnicas son bastante numerosas, sobre todo en lo que respecta a la caza.

Efectivamente, sólo se conoce un libro de equitación en los reinos hispánicos, el Livro de ensinaņ̧a de ben cavalgar toda sela, del mismo monarca portugués don Duarte. Pero la valoración del caballo y la equitación en la Baja Edad Media castellana, aparte del mismo interés por la caza, se nos muestra en los tratados para el cuidado del animal, tres de los cuales se escribieron entre mediados del siglo XIII y principios del XV ${ }^{49}$.

$\mathrm{Al}$ contrario que en otros países europeos, la clase de caza más valorada socialmente en Castilla es la cetrería. La mayoría de la literatura cinegética está dedicada a ella y no a la montería. Sin embargo, es probable que esta última tuviera un gran papel en la formación del joven aristócrata, como parece deducirse, además, de los monteros del conde de Haro y de los perros de caza de don Álvaro de Estúñiga, en los años centrales del siglo XV. En este mismo período, se ve realzada, además, como componente indispensable de las grandes fiestas cortesanas y señoriales, junto con los juegos de cañas y correr la sortija ${ }^{\text {so. }}$.

Quizás sea la música el arte más estimado en la Edad Media. El Vergel de principes de Rodrigo de Arévalo la propone como ocupación modélica de los nobles y le da un carácter religioso-moral, comparando la armonía musical con la celeste. Tañer un instrumento, cantar y danzar son los aspectos de esta instrucción más estrictamente cortesanos. Se encuentran entre las habilidades más apreciadas de los pajes y así, los Hechos del condestable Miguel Lucas de Iranzo nos muestran la participación de toda la Casa nobiliar en los rondeles y cosautes, poemas cantados y acompañados del baile, con ocasión de alguna

${ }^{48}$ Véase supra nota 47 y Don DuARTe, Leal Conselbeiro, p. 250 y ss. Hay también referencias a este punto en I. BECEIRO PITA, La biblioteca del conde de Benavente a mediados del siglo XV..., pp. 145-146. 274.

49 I. BECEIRO PITA, Los libros que pertenecieron a los condes de Benavente..., p. 264 y p.

30 I. BECEIRO PITA, La caza y la alta nobleza bajomedieval en el reino castellano, «Razo» núm. 3, «Cahiers du centre d'études médiévales de Nice», Nice, 1982, pp. 75-85. Para la importancia de la caza en la economía y en la mentalidad aristocrática de la Europa Occidental, véase La chasse au Moyen Age (Actes du Colloque de Nice, $22-24$ juin 1979), Nice, 1980. En cuanto a estas fiestas cortesanas, hay que resaltar especialmente las que tuvieron lugar con ocasión de la venida de Blanca de Navarra para su enlace con el futuro Enrique IV, Crónica de Juan II, en Crónicas de los reyes de Castilla, II, Madrid, 1953, B. AA. EE. pp. 565-566. 
fiesta o acontecimiento señalado en la vida del señor. El cuadro de las diversiones cortesanas se completa con los torneos literarios, muy frecuentes en la corte de Juan II, y los juegos de tablas y ajedrez"

A pesar de la afirmación de Helen Nader de que a los miembros del linaje de los Mendoza se les enseñaba a leer, a escribir, el latín, la geometría y la aritmética ${ }^{32}$, hay que poner muy en duda el conocimiento de estas dos últimas materias más que en algún que otro caso completamente excepcional. Incluso, aunque en menor medida, cabe extender la desconfianza al latín. Solo cambiará un poco el panorama sobre esta lengua en la época de los Reyes Católicos, como parece deducirse de las cartillas y gramáticas anotadas entre los libros de la reina y que, según Clemencín, debieron de pertenecer al príncipe Juan y a sus hermanas "s.

Hay que resaltar, una vez más, el gusto por la historia. Como ha señalado M. Bloch, es consustancial al grupo nobiliar junto con la literatura genealógica y el poema épico. En el reino castellano constituye uno de los elementos fundamentales de las bibliotecas nobiliarias. En cuanto a los testimonio sobre su estimación, al ya citado de don Juan Manuel hay que añadir el del segundo conde de Benavente, que resalta el valor de las enseñanzas transmitidas por los autores antiguos como ejemplo para las generaciones futuras, y el de Alfonso X, que recomienda que se lea a los caballeros en la comida, fragmentos históricos y cantares de gesta para mantener el ánimo belicoso en tiempo de paz ${ }^{34}$.

En líneas generales, la educación de las mujeres no sería radicalmente distinta, puesto que muchos nobles de ambos sexos sólo llegarían a saber leer y escribir. La diferencia se establece en una mayor insistencia para las mujeres en lo religioso y en las labores de hilado y costura, como se deduce de las disposiciones de Alfonso X: «E desque ovieren entendimiento para ello deuenlas fazer aprender leer en manera que lean bien las oras e sepan leer en salterio, $\mathrm{e}$ deuen puñar que sean bien mesuradas y muy apuestas, en comer, e en beuer, e en fablar e en su contenente e en su vestir e de buenas costumbres en todas cosas, sobre todo que no sean sañudas... E deuenles mostrar que sean mañosas en fazer aquellas labores que pertenescen a nobles dueñas" ". E. Power piensa

31 Rodrigo Sanchéz de ARÉvalo, Vergel de principes, en "Prosistas castellanos del siglo XV», I, CXVI, pp. 332-345; Hecbos del condestable Miguel Lucas de Iranzo, ed. de J. de M. Carriazo, Madrid, 1940, p. 156, y T. J. BoUDET, conde de Puymaigre, La cour littéraire de don Juan II, París, 1873.

\$2 H. NADER, Los Mendoza..., pp. 101-104.

33 D. ClemenCín, Elogio de la reina católica, Madrid, 1821, pp. 479-480.

${ }^{4} \mathrm{M}$. BLOCH, La sociedad feudal. La formación de los vinculos de dependencia, México, 1958, pp. 104-121; I. BECEIRO PITA, Los libros que pertenecieron..., pp. 241-242 y Las siete partidas, segunda partida, título XXI, ley XX, Madrid, 1807, II, p. 217.

"Las siete partidas, segunda partida, título VII, ley XI, Madrid, 1807, II, p. 51. 
que en los colegios monásticos franceses aprendían oraciones, a leer, coser e hilar, pero que es muy dudoso que las instruyeran en la escritura. El enriquecimiento del protagonista de Le miroir des nobles de Hesbaye se traduce en la educación que da a su hija: bordar, jugar al ajedrez y leer libros de horas y novelas, con lo cual pudo adquirir un marido de cierta posición ${ }^{36}$.

Es probable que muchas damas castellanas tampoco sobrepasaran el nivel de la lectura, pero el ideal debió de ser unir el aprendizaje de las labores de aguja con el de leer y escribir. Tiene su mejor expresión en la carta que don Francisco de Zúñiga envía a su hija, a fines del siglo XV, en donde le promete premiarla con unas joyas si al volver a casa la encuentra "gran labrandera letor[a] y escrivana»".

\section{LOS NOBLES COMO PROMOTORES DE EDUCACIÓN}

Si estas características son generales a todo el grupo, las iniciativas de fundar centros de enseñanza son aisladas e individuales. Su trasfondo es el patronato y el carácter de padre-protector que el noble ejercía sobre los que estaban sujetos a su señorío, el afán de absorber a la oligarquía concejil, y la conveniencia de formar futuros letrados que posteriormente podrían actuar como clientes y oficiales de su Casa. A este respecto, hay que señalar la creación de un colegio especializado o de un estudio local, de menor nivel.

En cualquier caso, los ejemplos conocidos son bastante escasos: a mediados del siglo XIV, Diego Gómez de Toledo, notario mayor de Pedro I, y su esposa Inés de Ayala, hermana del Canciller, fundan un colegio en la villa del Tajo. Situado en unas casas pertenecientes al matrimonio, fue puesto bajo la dirección de los agustinos, para la enseñanza de Teología y Artes. En 1470, la actitud de Miguel Lucas de Iranzo puede haber tenido un carácter más general y menos especializado: hace traer de Sevilla a sus expensas a un maestro de gramática para la instrucción gratuita en gramática, retórica, lógica y artes liberales de los vecinos del obispado de Jaén interesados en ello. Hay que enlazar estas iniciativas con las creaciones de centros de enseñanza por eclesiásticos surgidos de la nobleza territorial y urbana, más abundantes que las anteriores. Los ejemplos más sobresalientes son el colegio de San Clemente de los Españoles, en Bolonia, establecido en el siglo XIV por el cardenal Albornoz y el de Santa Cruz, en Valladolid, erigido por el cardenal Mendoza a finales del siglo $\mathrm{XV}^{s}$. 208.

s6 E. POWER, Mujeres medievales, pp. 102-103, y M. KeEN, La caballeria, p.

"7 Archivo Ducal de Alba, caja 246, núm. 43. Agradezco a Eduardo Pardo el haberme proporcionado este documento. 
Mucho más numerosos son los aristócratas y caballeros que encargan traducciones del latín o de otras lenguas, copias de libros, o realizan recopilaciones. Se encuentran entre ellos varios oficiales de la corte de Juan II, don Lorenzo Suárez de Figueroa, don Luis de Guzmán, maestre de la Orden de Calatrava, Ruy López Dávalos, el marques de Santillana y los condes de Benavente y Haro. Sus peticiones y, en ocasiones, su labor de síntesis abarcan tanto obras filosóficas e históricas del mundo clásico como la Biblia, la patrística y la filosofía moral de la transición entre la Antigüedad y la Edad Media, la literatura didáctica y la historia troyana, por citar solamente los temas más significativos.

En escasas ocasiones se atestigua el mecenazgo nobiliar sobre literatos y otros artistas, pero es probable que una investigación más exhaustiva arrojara más ejemplos, pues la figura de un escritor o artista plástico bajo la protección de un magnate es habitual en el período inmediatamente posterior a este. La relación de Gutierre Díez de Games con los Niño sólo entra parcialmente en estos supuestos, pero únicamente se le conoce como cantor de las glorias de don Pero. Sin embargo, a finales del siglo XV, el último maestre de Alcántara, Juan de Zúñiga, tiene como criado al latinista Nebrija, que mantuvo con él relaciones de amistad y dependencia durante diecinueve años, y el conde de Tendilla es el patrón de Pedro Mártir de Anglería. En las artes plásticas la relación debió de ser mucho menos estrecha, pero no cabe duda del papel de los Velasco en Burgos, a través de construcciones como su capilla funeraria y la casa del Cordón, que han llevado a pensar en un mecenazgo activo"

En fin, a pesar de que las noticias anteriores son muy escasas, todo hace suponer que los siglos XIV y XV, y sobre todo éste último, constituyen un período clave para el interés de los nobles por estos temas. J.N. H. Lawrance ha calificado esta última centuria como la de la difusión del conocimiento de la lectura y la escritura entre los laicos. Y, aunque el público de oyentes debió de subsistir, tal y como aparece anteriormente en los textos de Alfonso X el Sabio,

s8 La fundación de don Diego y doña Inés está citada en S. de Moxó, El auge de la nobleza urbana de Castilla y su proyección en el ámbito administrativo y rural a comienzos de la Baja Edad Media (1230-1370), "Boletín de la Real Academia de la Historia», CLXXVIII, cuad. III, Madrid, 1981, p. 177; Hechos del condestable Miguel Lucas de Iranzo, Madrid, 1940, p. 453. Para la creación del colegio de Santa Cruz, véase F. J. Villalba Ruiz de Toledo, Politica universitaria en la Castilla del siglo XV: el colegio de Santa Cruz de Valladolid, "En la España Medieval", V, Estudios en memoria del profesor D. Claudio Sánchez Albornoz, II, Madrid, 1986, pp. 1285-1297.

39 M. A. LADERO QUESADA, Mecenazgo real y nobiliario en monasterios españoles: los jerónimos (siglos XV y XVI), en Homenaje a José M." Lacarra. "Príncipe de Viana», 2, Anejo 3-1986, pp. 409-440; M. C. GERBET, La noblesse.., p. 332 y Epistolario de Pero Mártir de Angleria. 
es indudable la extensión de lectores individuales, que se refleja claramente en las bibliotecas nobiliarias formadas entre fines del XIV y mediados del XVI ${ }^{(6)}$.

ISABEL BECEIRO PITA

Centro de Estudios Históricos

(C.S.I.C.) Madrid

\section{RÉSUMÉ}

Cet article présente un panorama général de la culture nobiliaire castillane pendant le bas Moyen Age ainsi que les principales caractéristiques communes aux autres territoires hispaniques et à l'ensemble de l'Europe Occidentale. A cet effet on analyse deux aspects fondamentaux: d'une part, les personnes chargées de l'éducation et les espaces qui lui sont destinés, d'autre part, les connaissances et les techniques que les adolescents nobles devaient apprendre.

Dans le premier des cas la figure du précepteur se détache, ceci est au moins effectif entre les grandes familles. Il est probable que l'on réservait la responsabilité des tâches intellectuelles à un ecclésiastique, selon l'exemple de la monarchie. La cour gouvernante, la résidence seigneuriale et les écoles ecclésiastiques et municipales remplissaient aussi cette fonction auprès des vassaux, domestiques et élites urbaines.

Les renseignements et les documents sur le savoir de personnages concrets, les références littéraires et didactiques et les premiers antécédents du mécénat mettent en relief que, malgré la priorité donnée à l'équitation et à la chasse, on donnait un certain prix, en Castille, pendant le bas Moyen Âge et spécialement au XVème siècle, à la formation intellectuelle.

\section{SUMMARY}

This article presents a general scoop of the culture of the Castilian nobility during the Low Middle Ages and of the main common characteristics to other Hispanic territories and to the rest of Western Europe. It is the reason why we study two basic aspects: on the one hand, the people in charge of education and the spaces specially meant for it and, on the other hand, the knowledge and techniques that the young noble gentlemen had to learn.

${ }^{60}$ J. N. H. LAWRANCE, The Spread of Lay Literacy in Late Medieval Castile, «Buletin of Hispanic studies», LXII (1985) pp. 79-93. Véase también supra núm. 55. 
In the first one, appears the character of the tutor, at least in the great families. The weight of the intellectual tasks was probably reserved to a priest, as it was the use in the monarchy. The royal court, the seigniorial residence and the ecclesiastical and council schools accomplished also that function towards the vassals, servants and urban élites.

The documental news about the knowledge of specific characters, the literary and didactic references and the first records of patronage stress the interest of the intellectual training, though the priority given to riding, was evaluated in the Castilian Low Middle Ages, especially during the $\mathrm{XV}^{\text {th }}$ century. 